\title{
NA NEOCOLÔNIA: MODERNIDADE, MOBILIDADE, GLOBALIDADE
}

\section{Mary Louise Pratt}

New York University

Em 1928, o escritor uruguaio Horacio Quiroga publicou a famosa coleção de contos, Los desterrados, que se passam nas Missões, aquela área remota entre o Brasil e a Argentina, onde o autor tinha vivido por alguns anos. As histórias focalizam uma coleção de excêntricos, na maioria europeus desarraigados que tinham dado com os costados aí, nessa periferia da periferia, um por um, ao correr dos anos. Entre eles acham-se o francês Rivet, um químico que, após ter passado vinte anos na Argentina, industrial bem sucedido, aparece sem mais explicações e acaba morrendo por ingestão de álcool de lamparina junto com seu amigo Juan Brown. Brown tinha viajado para as Missões "por um par de horas, caso de ver as ruínas" e ainda por lá se achava quinze anos mais tarde (Quiroga 231). ${ }^{1}$ E havia o belga, especialista em explosivos, chamado Van Houten e apelidado "O-que-sobrou-de-Van Houten" porque tinha perdido "um olho, uma orelha e três dedos da mão direita" em acidentes. E o biólogo sueco, Dr. Else, que tinha sido parte de um time de especialistas europeus contratados pelo governo paraguaio para organizar hospitais, escolas e laboratórios, o qual, quinze anos mais tarde, aparece inexplicavelmente nas Missões vestindo "bombachas de soldado paraguaio, sapatos sem meias e uma boina branca encardida

\begin{tabular}{|l|l|l|l|l|}
\hline Ilha do Desterro & Florianópolis & no 57 & p. 019-036 & jul./dez. 2009 \\
\hline
\end{tabular}


puxada sobre um dos olhos." Num delírio alcoólico, Else mata a própria filha a pauladas, tomando-a por um rato gigantesco. Esse excesso por sua vez resulta de uma colaboração num experimento falido com o engenheiro braceta Luisser, cujo pertence mais precioso é uma edição em dois volumes da Encyclopédie de Diderot. As Missões são uma paródia do cosmopolitismo na periferia, e constituem também e ao mesmo tempo o coração da ordem neo-colonial.

Os "desterrados" de Quiroga são os anti-conquistadores da neocolônia, europeus apanhados nos confins do império na arapuca de um mundo americano que lhes tolheu a força de vontade. Carregam consigo as normas da modernidade metropolitana - a industrialização, o individualismo autogênico, a inovação, a ciência, a medicina, a racionalidade, o estado burocrático - mas não conseguem fazer com que essas normas entrem em funcionamento. O narrador de Quiroga se refere a eles como ex-hombres, um termo que expressa, além de alcoolismo e corpos mutilados, os sinais do colapso das relações de mobilidade, império, masculinidade, agência e cidadania que se supõe constituem a ordem nacional modernizante. Os trópicos vencem a teleologia da modernidade, que é a da sua difusão do centro para a periferia. Extraem dos ex-hombres "o pesado tributo que queima como álcool a atividade de tantos estrangeiros, e o colapso já não se detém mais" (207). A viagem rumo ao desconhecido passa do heróico ao ridículo esforço (fatal para Van Houten e Rivet), de voltar do bar para casa , embriagados. Há, sim, uma jornada heróica em Los desterrados, uma maratona de tirar o fôlego, contínua, dia e noite, de um funcionário municipal que luta para entregar os seus registros dentro do prazo. Mas também esse esforço épico se transforma numa parábola da modernidade periférica. Após triunfar sobre as forças da natureza, o herói burocrático é recebido com zombarias por ter levado a sério o regulamento.

Os ex-hombres de Quiroga são daqueles viajantes que, como o companheiro de Humboldt, Bonpland, não vão voltar para contar a história. Não é, porém, a relação deles com o problema de viagens que vou abordar aqui, mas a de Quiroga, que escreve Los desterrados do ponto de vista dos observados e dos recipientes dessas viagens e da 
literatura de viagem européias, a posição a que me refiro como a de "viajado" em contrapartida à de "viajante", a posição das gentes e lugares que são a meta dos viajantes. A observação é óbvia no sentido de que as histórias de Quiroga se contam do ponto de vista da América do Sul e dos muitos europeus que viajaram para aí. Mas há também um sentido mais interessante, em que viagens e relatos de viagens de europeus são parte do contexto imediato dos escritos de Quiroga, parte da matéria prima de sua criação, parte do que faz de Quiroga o narrador que é. Assim como o sugere o título, Los desterrados, as Missões surgem, não como um local, mas como uma meta, um destino. É o lugar que tem a força de interromper o paradigma circular de partida e retorno que produz a literatura de viagem. É um local de ex-ílio onde ex-hombres ex-cêntricos naufragam quando expulsos dos enredos-mestres da modernidade. A ordem colonial existe aí sob a forma de restos, nas ruínas de uma missão jesuíta. O narrador de Los desterrados retrata, do ponto de vista da recepção, uma ordem socioeconômica construída a partir de descontinuidades e deimprovisação, impropriedadee irresponsabilidade, uma abertura sem rumo ou destino. Aí a modernidade se mostra incapaz de se arraigar, uma incapacidade encenada dia após dia. Por mais que Luisser se esforce, as laranjas nativas não têm a doçura necessária para fazer um licor que satisfaça as exigências do mercado urbano. Por maior que seja a dedicação do tabelião ao estado, a chuva torna impossível a preservação de documentos. Ninguém sobrevive até uma idade mais avançada; não há mulheres. As Missões são uma paródia de progresso, e uma versão tragicômica do que teóricos latino-americanos costumam chamar de modernidade periférica. ${ }^{2}$

Frequentemente consideram-se as primeiras décadas do século XX como a era em que a modernidade se consolidou na América Latina. Foi a época em que se democratizou a participação política, em que emergiram uma classe média e, concomitantemente, um mercado de consumo, em que se deu uma certa industrialização, uma transformação tecnológica da vida quotidiana, e em que apareceram movimentos políticos tais como sindicatos, feminismo, comunismo, anarquismo. Consolidando as suas fronteiras, às vezes por meio de guerras 
sangrentas, os estados independentes da América Latina construíram culturas nacionais seculares fortes, apoiados em sistemas de educação pública e outras instituições culturais. Os centros urbanos cresceram e disputaram o poder com as aristocracias rurais. No domínio das artes, floresceram o rádio, a fotografia, o cinema e movimentos de vanguarda. Intelectuais se tornaram os porta-estandartes da modernidade e dos valores metropolitanos. Ao mesmo tempo, no entanto, as relações políticas e econômicas da América Latina continuaram em estado neocolonial. Ou seja, a América Latina continuou inserida num sistema internacional em quem, embora nominalmente independentes, seus estados-nação exerciam um controle fraco sobre os próprios destinos.

Num livro que se tornou famoso, o estadista ganaense Kwame Nkrumah, que liderou a luta de Ghana pela independência nos anos cinqüenta, designou o neo-colonialismo como "último estágio do imperialismo". Segundo Nkrumah, "a essência do neo-colonialismo é que o Estado sujeito a ele aparece, em teoria, independente, e tem todos os atavios da soberania internacional. Na realidade, porém, seu sistema econômico, e, portanto, suas decisões políticas, são dirigidos de fora," geralmente por meios econômicos e monetários, como, por exemplo, "os controles sobre o comércio exterior e sobre os bancos" (ix-x). A situação neocolonial é desagradável. Politicamente, traz todas as obrigações de um estado-nação, sem a autoridade de estabelecer o próprio itinerário político ou econômico. Enquanto a modernidade imagina um processo progressivo que tornará todas as nações igualmente modernas, o neo-colonialismo limita as possibilidades de desenvolvimento. $\mathrm{O}$ lucro da produtividade nacional se vai para os bolsos dos investidores estrangeiros. Culturalmente acontece um fenômeno análogo. Ser moderno quer dizer aceitar os valores culturais da metrópole e tentar cumprir os seus ditames. Ser neocolonial quer dizer ser incapaz de fazê-lo e, ao mesmo tempo, ser incapaz de sair do sistema e traçar um caminho diferente. As normas que emanam da metrópole e aterrissam na periferia se tornam o que o crítico brasileiro Roberto Schwarz chama de "idéias fora do lugar". ${ }^{3}$ O problema neocolonial, então, é o seguinte: as normas geradas fora não podem ser 
implementadas aqui, mas também não podem ser recusadas. Os daqui são forçados a tomarem a posição de membros de segunda classe de um clube a que é obrigatório pertencer. "Entre nós," diz o teórico chileno José Joaquín Brunner, "o constrangimento cultural não vem da exaustão da modernidade, mas da irritação com ela" (39).

Para escritores e artistas esse constrangimento se torna uma fonte de criatividade e experimentalismo, além de irritação. Em outros escritos examino o pelotão de viajantes do norte da Europa cujos relatos textualizaram a neocolônia hispano-americana após os movimentos de independência, e a forma pela qual as elites letradas dessas novas repúblicas reprocessaram esses relatos a fim de construir imaginários nacionais ex-e neo-coloniais. ${ }^{4}$ Neste ensaio, examino a forma pela qual a literatura latino-americana do século XX aborda o problema do neocolonialismo por meio dos códigos de relatos de viagem e do conceito de mobilidade. Neste período, escritores usam a posição de destinatários (de pessoas e mercadorias - a exportação neocolonial) como ponto de referência perene a fim de negociar o conceito e a representação da identidade pessoal e nacional. Em outras palavras, esses autores perguntam, assim como pergunta Quiroga: como fazer da meta, ou do destino dos outros um lar para si?

\section{Meta e destino: a modernidade neocolonial-1920-1950}

Como fazer da meta dos outros um lar para si? Poderíamos começar com um dos mais conhecidos locais ficcionais de toda a América Latina, o Macondo de Gabriel García Márquez, onde se passam os Cem anos de solidão (1962). Desde o encontro inicial com o misterioso bloco de gelo trazido pelos ciganos, Macondo passa a existir como meta e receptor. Tempo e história são aí marcados pelas chegadas imprevisíveis e incontroláveis de gente, coisas, instituiç̧ões e significados vindos de alhures. Os habitantes absorvem, examinam, ajustam, aceitam, adaptam, inventam, gozam, administram, sem saber nada sobre a origem e proveniência de tudo isso. Macondo é como o reverso de todo o corpo das narrativas de viagem européias à América. Esse corpo nos 
conta a história do envio e do retorno; García Márquez, assim como Quiroga, conta a chegada e a recepção. Em Macondo a modernidade chega mágica, mas neocolonialmente, sem ser convidada, aos pedaços - o piano mecânico, a estrada de ferro, a companhia de bananas. Torna-se a matéria prima com que os personagens, assim como o romancista, negociam, interagem e criam.

Mais recentemente, num romance intitulado La ciudad ausente (1997) o romancista Ricardo Piglia apresenta seu protagonista como um descendente de viajantes ingleses do século XIX que "abandonaram as suas famílias e amigos para viajar por regiões às quais ainda não havia chegado a revolução industrial. Solitários e quase invisíveis, inventaram o jornalismo moderno porque deixaram para trás as suas histórias pessoais" (9). Essa genealogia é a chave que leva aos temas principais do romance: é impossível pertencer, e a história é irrecuperável. Mais uma vez, a identidade da América Latina como meta e destino torna-se a condição que define o escrever e o viver. $\mathrm{O}$ problema neocolonial torna-se uma máquina de auto-invenção. Escritores tais como Piglia, García Márquez e Quiroga trabalham, em vários sentidos, a configuração de relações que a neocolônia vive.

Esse trabalho é um aspecto diferenciador e criativo dos modernismos latino-americanos. Frequentemente aparece sob a forma de uma crise do pertencer, do auto-enquadramento, expressa em termos de viagens. Por exemplo, a maioria dos estudantes sérios de literatura latino-americana conhece o ensaio de Alejo Carpentier, "De lo real maravilloso americano", escrito no fim dos anos quarenta. É fácil esquecer que o ensaio é na realidade um relato de viagem, propositalmente desalinhado que marca a diferença neocolonial entre o viajante americano e sua contrapartida européia. Nesse ensaio fascinante, a diferença neocolonial se marca acima de tudo como uma diferença de autoridade, uma diferença naquilo que é permitido saber e dizer sobre o outro. Carpentier abre o ensaio com uma descrição de suas viagens à China, um catálogo de maravilhas que ele acaba dizendo não ter entendido: 
Vi muitas coisas extremamente interessantes. Mas não estou certo de as ter compreendido. Para compreender realmente... teria sido necessário conhecer a língua e ter noções claras sobre uma das mais antigas culturas do mundo. $(67)^{5}$

O que mais lhe faltava, continua, era conhecer os livros, "uma compreensão dos textos". E quando de sua viagem ao Oriente Médio, nada sentiu mais do que "la gran melancolía de quien quiso entender y entendió a medias" (a grande melancolia de quem queria entender e só entendia pela metade). Carpentier sempre sente que a sua maior falha é o seu desconhecimento de livros "algún antecedente literário, de la filosofia" (68). É raro viajantes europeus expressarem esse tipo de malestar (para voltar a Brunner) quanto à sua ignorância. As convenções do gênero não o pedem. Mas, pelo jeito, ao viajante provindo da neocolônia, essa ignorância não é permitida. Sem conhecer os livros, não tem licença para escrever. Carpentier continua: quando chegou à Rússia, o universo se tornou inteligível. Encontra nomes de lugares de que ouviu falar (em romances russos), edifícios que conhece por fotografias, pontos de contato histórico com a América. E quando chega a Praga, finalmente, fica à vontade. As pedras lhe falam de Schiller, Kepler, Kafka.

Mas mesmo nesse universo familiar, o relato de viagem de Carpentier revela um contraste fascinante em relação aos de viajantes metropolitanos. Carpentier reconta esse mundo conhecido da Europa ocidental não em atos de representação, mas em experiências de reconhecimento. Ou seja, ele não constrói imagens evocativas com as suas palavras, tentando recriar o que viu na imaginação dos seus leitores. Pelo contrário, o que reconstrói são vistas já conhecidas a partir de outras viagens ou de "antecedentes literários". Carpentier não toma a si a autoridade européia de representar, descrever, ou re-criar o que vê. A única autoridade que toma é a de exprimir um reconhecimento do que já sabia, por ter aprendido e por the terem ensinado, que isso existia. Por que? Talvez por que lhe falte um público: quem leria, nos anos quarenta, um livro de viagens à China, à Polônia, ou ao Oriente Médio, escrito por um cubano? Os modernistas latino-americanos 
frequentemente acusam Carpentier de ser "europeizante". Mas mesmo se seus textos são eurocêntricos, não os governam os códigos europeus de relações de viagem. Ele é "europeizante" de uma forma inegavelmente americana e, pode-se dizer, neocolonial. Creio que sua insistência constrangida em considerar essenciais ao viajante conhecimentos tirados de livros reflete a situação cultural do intelectual da periferia para quem a realidade e a história "reais" foram vividas alhures. O viajante de Carpentier é o retrato do autodidata neocolonial, cuja biblioteca particular constitui a base para a sua candidatura à modernidade - tal qual os habitantes de Macondo, ou o engenheiro de Quiroga com os seus dois volumes de Diderot.

Mas Carpentier não perde completamente a experiência da descoberta. Encontra-a quando volta a Cuba, onde descobre...Cuba. E assim nos dá essa sentença famosa: "vuelve el latinoamericano a lo suyo y empieza a entender muchas cosas" (o latino-americano volta ao que é seu e começa a entender muitas coisas) (72). A viagem ao exterior lhe proporciona uma visão nova da América neocolonial: constitui uma auto-construção inovadora, e não um reflexo empobrecido da Europa. E faz assim uma espécie de declaração de independência estética:

O latino-americano arrasta consigo um legado de trinta séculos... mas é preciso acrescentar que seu estilo se forma por meio do desenrolar de sua própria história, mesmo que esse estilo acabe engendrando verdadeiros monstros. (73, ênfase do autor) ${ }^{6}$

A partir dessa observação, o ensaio começa a criar uma ótica descolonizadora enquanto que, ao mesmo tempo e ironicamente, continua se atendo ao antecedente europeu. Carpentier viaja ao Haiti, e visita o palácio e a fortaleza do rei Henri Christophe, o governante negro que aí se instalou depois que a grande revolta dos escravos derrubou os franceses que tinham governado a ilha. Guiado pela figura de Josephine, a esposa martiniquense de Napoleão, Carpentier tem uma visão nesse local, que o leva a aplicar os seus conhecimentos de 
cultura européia de uma forma inteiramente nova à sua pátria caribenha:

Vi a possibilidade de trazer certas verdades européias às nossas latitudes, agindo a contrapelo dos que, viajando em direção oposta à do sol, quiseram levar as nossas verdades para o estrangeiro, onde, há trinta anos, ainda não existia a possibilidade de compreendê-las nem medidas para lê-las em suas dimensões justas. $(73)^{7}$

Mais uma vez, a viagem é o código que expressa a relação neocolonial. Ao trazer verdades européias para as suas latitudes, Carpentier descobre que na América sobrevive uma parte da Europa que já não vive mais na Europa. Nas culturas populares das Américas, certas práticas e crendices que têm raízes na Idade Média, particularmente a crença no maravilhoso, continuam a medrar muito depois de terem sido destruídas na Europa pela secularização racionalista que Max Weber chamou de desencanto. Esse ingrediente europeu não-modernizado, decide Carpentier, é o que torna a América (ou, no caso, o Caribe) autenticamente encantada, maravilhosa. Comparado a ela, o surrealismo europeu foi inautêntico, uma "tentativa cansativa de ressuscitar" o maravilhoso depois deste ter sido morto. Essa idéia de Carpentier perturba seus leitores, porque mesmo nesse momento descolonizador, a autenticidade cultural da América ainda repousa em seu legado europeu, enão, por exemplo, na contribuição de suas populações indígenas ou de origem africana. O próprio Carpentier, mais de uma vez, se identifica com os conquistadores. ${ }^{8}$ Carpentier resolve o problema neocolonial re-imaginando a sua relação com a Europa sob a forma não de alteridade, mas de autenticidade. Por meio desse gesto de colonização e descolonização simultâneas, a meta dos outros se torna o lar de um eu unificado, branco, "criollo".

O novo sujeito cultural americano de Carpentier nasce em viagem - num itinerário que não dá a volta à metrópole, mas passa por ela, $\mathrm{e}$ retorna. $\mathrm{O}$ caminho que leva à descolonização e à subjetivação não dá a 
volta aos códigos da modernidade, mas passa por dentro dela. A literatura americana do século XX está cheia de manifestos de retorno, desde o Cahier d'un retour ao pays natal de Aimé Césaire, à Rayuela de Julio Cortazar, ao Canto general de Pablo Neruda, ao Pedro Páramo de Juan Rulfo, e à "Vuelta" de Octávio Paz. Mas a viagem dentro das Américas, especificamente ao Haiti, é igualmente essencial ao momento de iluminação epistêmica de Carpentier. Relatos de viagens regionais e nacionais representam um papel-chave no arquivo do modernismo latino-americano. A neocolônia precisa desenvolver e sustentar pelo menos duas formas de capital cultural: o capital nacional (que se constitui de formações locais e regionais), e um capital cosmopolita/universal (de formações européias e da Grécia e Roma clássicas). Até hoje, livrarias na América latina têm estantes separadas para a "literatura nacional" e a "literatura universal". Na Europa, os movimentos modernista e vanguardista dos inícios do século XX foram resolutamente cosmopolitas e continentais e mesmo anti-nacionalistas. Mas nas Américas, pelo contrário, a constituição de um capital cultural nacional foi uma das preocupações centrais de artistas e movimentos artísticos do início desse século, inclusive no caso das vanguardas. Às pessoas instruídas cabia a responsabilidade de construir as nações modernas e criar o capital cultural que definiria seus cidadãos e criaria o seu senso de comunidade nacional; era comum escritores serem diplomatas, servidores públicos, professores, presidentes.

Essa responsabilidade de construir nações pode bem ser a razão pela qual os modernismos latino-americanos tiveram eixos tanto urbanos quanto rurais. Na Europa, o modernismo e o experimentalismo literário foram fenômenos quintessencialmente urbanos. A paisagem literária da neocolônia, pelo contrário, aparece pontilhada de experimentos que expressam ilustração e cidadania em termos nãourbanos. Nos anos trinta e quarenta, por exemplo, a poeta chilena Gabriela Mistral, recipiente do Prêmio Nobel de Literatura em 1942, de quem falaremos logo mais, escreveu uma obra imensa, que chamou de Poema de Chile. Inclui mais do que trezentas composições, e é o relato de uma viagem imaginária em que o "eu" poético atravessa a paisagem 
chilena na companhia de uma criança indígena. ${ }^{10}$ Tal como o ensaio de Carpentier, o Poema de Chile constitui um retorno e uma redescoberta, em que a poeta volta ao seu país natal após uma longa ausência, como um fantasma. Além de ter um escop o nacional, a obra é veementemente rural, e, de fato, anti-urbana. A posição de Mistral como professora rural, maestra rural, constitui o centro de gravidade de sua identidade moderna e de sua fama internacional.

Em 1941 um contemporâneo de Mistral e Carpentier, o escritor peruano José María Arguedas, terminou o seu extraordinário romance de estréia, Yawar Fiesta. Arguedas, filho de um advogado itinerante, se criou nos Andes numa aldeia onde morou com uma família indígena, aprendeu Quechua, e se identificou profundamente com a geografia e a cultura andinas. Como escritor e ativista cultural, impôs a si mesmo a tarefa de superar a barreira colonial, cultural e racial que fragmenta a sociedade peruana e mantém a maioria indígena marginalizada e subordinada. Seu romance, cujo título significa "Festa de sangue," começa com uma cena de chegada que explicitamente substitui a figura do viajante estrangeiro pela do nativo que volta. Ou seja, quem chega é um andino e não um forasteiro; a linguagem tem uma qualidade oral e local:

Entre campos de alfafa, chácaras de trigo, de favas e de cevada, sobre um morro escarpado, fica a vila.

Partindo do passo de Sillanayok se vem três riachos, juntandose pouco a pouco, à medida que chegam à quebrada do rio grande. Os riachos caem das punas correndo por gargantas íngremes, mas se detém depois numa pampa desigual onde até se formou uma laguna; a pampa termina e o curso dos rios se quebra de novo e a água vai saltando de catarata em catarata até chegar ao fundo da quebrada.

A vila se vêgrande, em cima do morro, seguindo as escarpas.(19)

Arguedas - e é aí que mostra o seu gênio - introduz o mundo andino de uma forma que permite que seja decifrado por leitores nãoandinos e ao mesmo tempo mostra claramente que nos encontramos 
num universo diferente. No trecho acima, por exemplo, o local não se mapeia por meio de formações geológicas, mas pela água corrente. (Em vilas andinas, a água corre por canais construídos ao longo e por vezes no meio das ruas.) Após esta chegada andina, Arguedas introduz a voz do forasteiro, "el viajero," o viajante, que dá nome aos lugares por meio da forasteira nomenclatura racista: "pueblo índio". Pueblo índio, explica o narrador, é o que dizem os viajantes quando, na saída do desfiladeiro, vêm a vila, Puquio, lá embaixo. "Unos hablan con desprecio; tiritan de frío en la cumbre los costeños, y hablan ‘Pueblo índio!'” (Eles falam com desprezo; tiritam de frio no cume, essa gente da costa, e dizem "vila de índio") (20). Mas, como lembra o narrador, esses viajantes vem da costa; vivem ao nível do mar. Como nunca viram as suas próprias vilas de cima, não entendem a "alegría del corazón que conoce las distancias" (22). Os montanheses cantam ao avistarem a vila natal longe, e abaixo. Essa abertura complexa, translinguística e intercultural deslancha um experimento de escrita organizado em torno da tourada anual da vila. Arguedas entrelaça a visão moderna e nacional dos que chegam com a do povoado, num mundo andino regido pela conjunção, e talvez fusão, de relações coloniais com o universo indígena.

Arguedas invoca, e depois desloca, os viajantes não-indígenas com seus termos depreciativos e alterizantes e estabelece em seu lugar o nativo que retorna. Eassim transforma Puquio de meta em lar. Para os modernistas da neocolônia, a descolonização manda que se passe, não em volta, mas através dos discursos metropolitanos produtores do sujeito colonial.

Um dos grandes experimentalistas do modernismo brasileiro, Mário de Andrade, insistia nisso mesmo. Seu grande relato cômico de viagem, Macunaíma, marco do movimento, originou-se como uma paródia da Viagem ao Brasil 1817-1820 de Karl Martius. ${ }^{11}$ Diz Andrade num prefácio:

Um dos meus interesses foi desrespeitar lendariamente a geografia e a fauna geográficas. Assim desregionalisava o mais possível a criação ao mesmo tempo que conseguia o mérito de conceber literariamente o Brasil como entidade 
homogênea, um concerto étnico nacional e geográfico. (Dizer também que não estou convencido...de ter feito obra brasileira. Não sei se sou brasileiro. É uma coisa que me preocupa e em que trabalho porem não tenho convicção de ter dado um passo grande prá frente não). (Macunaíma356) ${ }^{12}$

Andrade não duvida literalmente de ser brasileiro - tal como Arguedas, nunca foi à Europa. Nesse trecho, ele evoca o problema cultural neocolonial. Se basta trabalhar com os discursos europeus herdados colonialmente, ele só pode criar algo autenticamente brasileiro se usar esses discursos de uma forma conscientemente inautêntica. Numa análise brilhante da prosa e fotografia de Andrade, Esther Gabara mostra como ele cria "uma prática de representação e autorepresentação 'errantes'" (25). A prática descolonizadora de Andrade, conforme Gabara, consiste em criar uma inautenticidade autenticamente brasileira ao desapropriar e desorganizar os discursos metropolitanos do relato de viagem, da geografia, da etnografia. Andrade também escreveu uma paródia muito engraçada de um relato de viagem, $O$ turista aprendiz, baseado em suas viagens pelo interior do Brasil. Nessa obra usou imagens fotográficas sobrepostas para remexer os códigos. Especialmente, como mostra Gabara, sobrepôs retratos (uma forma de arte do eu e do lar) a paisagens (forma de arte do longe e do alhures). Numa foto cômica intitulada "Aposta ridícula em Teffé, 12 de junho, 1927", Andrade porta a bengala e o chapéu do naturalista europeu, a banana do indígena "selvagem" e do afrobrasileiro, e o leque da sinhá fazendeira. Observa Gabara: "Os símbolos das assim-chamadas 'três raças' brasileiras se sobrepõem comicamente recusando transformarem-se no retrato de um corpo nacional único e unificado" (17). Só o que tem em comum é o próprio colonialismo, que é também o que os separa. Andrade se engalfinhou com o problema nacional de forma cômica, mas também falou da dor que esse pode causar, a "dor sulamericana do indivíduo," como a descreveu em carta, uma dor que europeus não imaginam e que "me deslumbr[a] e afet[a]". Emanando da conquista e de suas sequelas, esse sofrimento consiste 
na "incapacidade realizadora do ser moral". Para Andrade é essa uma "dor imensa e sagrada: sempre imaginei que ela viajara na primeira vela de Colombo e vive aqui" (Gabara 26). ${ }^{13}$

Uma dor sagrada semelhante e uma estratégia de superposição parecida aparecem num dos maiores poemas de Gabriela Mistral. No trabalho que produziu nos anos 30 e 40, a mobilidade e as viagens mais uma vez articulam a crise do desejo e do pertencer que constitui o problema cultural da neocolônia. Um dos poemas que mais atraíram o primeiro tradutor de Mistral, Langston Hughes, se entitula "La extranjera". Esse belo poema usa o equivalente verbal da sobreposição fotográfica do lar e do alhures que vimos em Andrade (Mistral, Poesías 152). ${ }^{14}$ Assim como Arguedas repete o tom hostil com que o viajante de fora resmunga pueblo índio, o poema de Mistral é a fala de uma voz sem nome que descreve a estrangeira como uma intrusa que não pertence: "Habla con dejo de sus mares bárbaros / Con no sé qué algas y no sé qué arenas" (fala com o sotaque de seus mares bárbaros, com não sei que algas e não sei que areias). Tal como a "Aposta ridícula em Teffé", a "Estrangeira" de Mistral é um auto- retrato refratado através da voz de um "outro" forasteiro. Imagens estereotipadas da América do Sul como natureza aparecem, tal com aparecem na foto de Andrade, como um código cultural comum: "En huerto nuestro que nos hizo extraño / ha puesto cactus y zarpadas hierbas" (Poesías II: 5-6). O pertencer incompleto dessa forasteira é uma condição permanente. Mesmo que "viva entre nós por oitenta anos," como diz o poema,

...siempre será como si llega

hablando lengua que jadea y gime

que le entienden solo bestezuelas (Poesías II, 12-14).

Essa condição, assim como a que descreve Andrade, é irremediavelmente dolorosa. "Ela há de morrer," conclui o poema, "uma noite quando for mais agudo o seu sofrimento, só com o destino por almofada" (Poesias II: 15-17). ${ }^{15}$ Não é essa a mesma dor que, segundo Andrade, cruzou os mares com Colombo? 
Mistral escreveu um poema companheiro de "La extranjera," "País de la ausencia" que aborda o problema do pertencer de forma complementar. Ao invés da superposição de elementos diversos numa imagem fotográfica, o "país da ausência" constrói algo como uma chapa vazia, uma foto cuidadosamente composta de nada. A poeta pinta um lugar do pertencer composto de ausências, negações e perdas. O seu país "sem nome", como diz, "não dá nem romãs, nem jasmim / não tem céus nem mares de anil... nem ponte nem barco me trouxeram a ele... não o procurei nem o descobri" (151). Observa-se como esses versos referenciam os mitos da América e logo os deixam de lado. O país da poeta é um lugar que compreende as "pátrias que eu tive e perdi":

Perdi cordilleras
En donde dormí
Perdi huertos de oro
Dulces de vivir
Perdí yo las islas
De caña y anil... (Poesías II: 39-44)

(Perdi cordilheiras / onde dormi / perdi hortas de ouro / doces de viver / perdi as ilhas / de cana e anil). Para Mistral, as sombras de todas essas coisas dançam à sua volta gentilmente, para compor "esse país sem nome onde vou morrer". Tal como Gertrudis Gómez de Avellaneda em "Viajero americano", Mistral evoca os mitos fundamentais da América a fim de apagá-los. Coloca em seu lugar o nada - a presença da ausência - propondo um vácuo semântico como uma forma de plenitude. Dessa forma engenhosa, "Pais de la ausencia" se livra da retórica viajante de meta e destino. A terra da ausência não pode ser meta; é um lugar que passa a existir quando se deixam para trás outros lugares e outras histórias.

Desta forma Mistral, Carpentier, Arguedas, Andrade, e tantos outros seus contemporâneos aplicam a força e o destemor da visão artística ao tratarem do problema neocolonial. O neocolonialismo impõe diversas perdas de liberdade; o desenvolvimento e o florescimento de 
quase tudo sempre vêm de uma luta a contrapelo. Ao mesmo tempo, formações culturais várias, ou formas de capital cultural, entram em jogo - regionais, nacionais, e metropolitanas/universais. Os artistas encontram possibilidades de invenção entrelaçando-as e superpondo umas às outras com engenho e arte, como o fez Andrade com suas fotos de exposição superposta e mutualmente refratadas, ou como Arguedas com as suas fusões excruciantes. Talvez esses modernistas estivessem tentando fazer o que a crítica pós-colonial Vinay Bahl (1997) considera um feito impossível - "chegar a uma auto-definição em oposição à definição por alteridade que lhes impõem as forças imperialistas, sem se deixarem consumir por essas categorias" ("Cultural Imperialism" 12).${ }^{16}$ A reação dos modernistas a esse desafio é um perpétuo devenir.

\section{Notas}

1. Partes deste capítulo constituem uma revisão do meu ensaio "Modernity, Mobility and Excoloniality."

2. Beatriz Sarlo, Una modernidad periferica: Buenos Aires, 1920 y 1930.

3. Roberto Schwarz, Misplaced Ideas.

4. Vide Pratt, Os olhos do império.

5. "He visto muchas cosas profundamente interesantes. Pero no estoy seguro de haberlas entendido. Para entenderlas realmente...hubiese sido necesario conocer el idioma, tener nociones claras acerca de una de las culturas más antiguas del mundo".

6. "Arrastra el latinoamericano una herencia de treinta siglos, pero...debe reconocerse que su estilo se va afirmando a través de su historia, aunque a veces ese estilo puede engendrar verdaderos monstruos".

7. "Vi la posibilidad de traer ciertas verdades europeas a las latitudes que son nuestras actuando a contrapelo de quienes, viajando contra la trayectoria del sol, quisieron llevar verdades nuestras adonde, hace todavía treinta años, no había capacidad de entendimiento ni de medidas para leerlas en su justa dimensión".

8. Fazendo pouco da observação de Lautréamont sobre os adolescentes que têm prazer em estuprar os cadáveres de mulheres bonitas, Carpentier observa que "o 
maravilhoso seria violá-las vivas" (75). O subconsciente colonial nunca fica longe, codificado em ideologias que cruzam as fronteiras do império.

9. Uso o termo espanhol, que significa "nascido na colônia", por ter sido adotado, com esse mesmo sentido, em inglês e por não corresponder, nesse sentido, ao cognato em português. (Nota da tradutora.)

10. Gabriela Mistral. Poesias completas.

11. Para uma análise detalhada de sua relação com a literatura de viagem à Amazonia, vide Lúcia de Sá, Rain Forest Literatures: Amazonian Texts and Latin American Culture.

12. Citado em Esther Gabara, The Ethos of Modernism: Photography and Literature in Brazil and Mexico, 1920-1940.

13. Segundo Andrade, "europeus por outro lado não sofrem, teorizam o sofrimento". Vide Mário de Andrade, O turista aprendiz (Gabara 26).

14. Gabriela Mistral, "La extranjera" in Tala (1938), coletado em Gabriela Mistral, Poesías. Traduzido para o inglês por Langston Hughes em Selected Poems of Gabriela Mistral. Nota da tradutora: com algumas exceções, em que a tradução é minha, deixo os poemas em espanhol.

15. "ya va a morirse em medio de nosostros / en una noche en la que más padezca / con solo su destino por almohada".

16. Ver também, da mesma autora, "On the Relevance (or Irrelevance) of Subaltern Studies," Economic and Political Weekly 32:23, p. 1333-44, June 1997.

\section{References}

ANDRADE, MÁRIO DE. Macunaíma: o herói sem nenhum caráter. São Paulo: Martins, 1978.

Obras completas. São Paulo: Martins, 1955-66.

ARGUEDAS, JOSÉ MARIA. Yawar Fiesta. Lima: Editorial Horizonte, 1980.

BAHL, VINAY.Cultural Imperialism and Women's Movements: Thinking Globally. Gender and History 9.1 (Abril 1997): 1-14. 
. On the Relevance (or Irrelevance) of Subaltern Studies. Economic and Political Weekly 32. 23 (June 1997): 1333-44.

BRUNNER, JOSÉ JOAQUIM. Bienvenidos a la modernidad. Santiago: Planeta, 1994.

CARPENTIER, ALEJO. Tientos y diferencias y otros ensayos. Barcelona: Plaza y Janés, 1987.

GABARA, E.; Errant Modernism: The Ethos of Modernism: Photography and Literature in Brazil and Mexico, 1920-1940. Durham, NC: Duke UP, 2008.

GARCÍA, G. M.; Cem anos de solidão Rio de Janeiro: Record, 1992.

MISTRAL, G.; Poesías. México: Porrúa, 1986.

. Poesias completas. Ed. Margaret Bates. Madrid: Aguilar, 1966.

. Selected Poems of Gabriela Mistral. Trad. Langston Hughes. Bloomington, IN: Indiana UP, 1957.

NKRUMAH, K.; Neocolonialism: The Last Stage of Imperialism. New York: International Publishers, 1965.

PIGLIA, R.; La ciudad ausente. Buenos Aires: Sudamericana, 1992.

Pratt, Mary Louise. Modernity, Mobility and Excoloniality," Seuils et Travesrses: Actes du Colloque de Brest. Brest: Centre de Recherche bretonne et Celtique, 2002. 13-30.

. Os olhos do império: relatos de viagem e transculturação. São Paulo: EDUSP, 1999.

Quiroga, Horacio. Los desterrados y otros textos. Ed. Jorge Lafforgue. Madrid: Clasicos Castalia, 1990.

Sá, Lúcia de. Rain Forest Literatures: Amazonian Texts and Latin American Culture. Minneapolis: U of Minnesota P, 2004.

Sarlo, Beatriz Sarlo. Una modernidad periferica: Buenos Aires, 1920 y 1930. Buenos Aires: Nueva Visión, 1988.

Schwarz, Roberto. Misplaced Ideas. Ed. John Gledson. London: Verso, 1992. 